DOI: https://doi.org/10.15688/nsr.jvolsu.2019.1.7

UDC 338:502.72(470.45)

LBC 65.9(2P-4Вог)28

\title{
PROSPECTS FOR IMPROVING THE NATURE PROTECTION EFFICIENCY OF THE WILDLIFE PRESERVE OF THE VOLGOGRAD REGION
}

\author{
Anna V. Kholodenko \\ Volgograd State University, Volgograd, Russian Federation \\ Aleksandra V. Grebennikova \\ Volgograd State University, Volgograd, Russian Federation
}

\begin{abstract}
Qualitative assessment of the current and perspective nature protection efficiency of specially protected natural areas as forms of the animals, plants biodiversity conservation directly in habitats and unique landscapes for optimization of territorial conservation is necessary. Environmental efficiency can be an assessment parameter of the completeness of the certain specially protected natural areas implementation, caused by its belonging to a category, the status, natural and ecological features of the territory. The technique developed by WWF of Russia in 2012 and published by M.S. Stishov is effective for such research. An advantage of this technique consists in an opportunity to estimate results in the sphere of conservation for some specially protected natural areas and their regional systems as in the current conditions, and in the long term, including at change ecological situations. Wildlife preserves areas of the Volgograd region which make $15 \%$ of total number of natural protected areas of the region acted as the main object of research and occupy $26 \%$ of the total area of protected areas, belong mainly to a faunal area. The contribution of wildlife preserves to the saving of regional biological and landscape diversity is very significant, especially in the absence of natural sanctuaries as a priority form of territorial conservation in the specially protected natural areas system of the Volgograd region. As a result of research, we estimated values of nature protection relevance, significance and effectiveness of wildlife preserves in the Volgograd region. Factors influencing realization of nature protection function by specially protected natural areas are allocated. The result received can be considered as a basis for plan of increase in the effectiveness of each wildlife preserve of the Volgograd region.
\end{abstract} efficiency.

Key words: biodiversity, specially protected natural areas, Volgograd region, wildlife preserve, environmental

УДК 338:502.72(470.45)

ББК 65.9(2Р-4Вог)28

\section{Әे ПЕРСПЕКТИВЫ ПОВЫШЕНИЯ ПРИРОДООХРАННОЙ ЭФФЕКТИВНОСТИ ГОСУДАРСТВЕННЫХ ПРИРОДНЫХ ЗАКАЗНИКОВ ВОЛГОГРАДСКОЙ ОБЛАСТИ}

\author{
Анна Викторовна Холоденко \\ Волгоградский государственный университет, г. Волгоград, Российская Федерация \\ Александра Владимировна Гребенникова \\ Волгоградский государственный университет, г. Волгоград, Российская Федерация
}

Аннотация. Для оптимизации территориальной охраны природы необходима качественная оценка текущей и перспективной природоохранной эффективности функционирования ООПТ как приоритетной формы сохранения биологического разнообразия животных, растений непосредственно в местах обитания, 
и уникальных ландшафтов. Природоохранная эффективность может служить оценочным параметром, характеризующим полноту реализации конкретной ООПТ ее основных природоохранных задач, обусловленных принадлежностью к категории, статусом и природными особенностями территории. Результативной для подобных исследований является методика, разработанная WWF России (Стишов M.C., 2012 г.), преимущество которой заключается в возможности оценивать результаты в сфере охраны природы для отдельных ООПТ и их региональных систем как в текущих условиях, так и в перспективе, в том числе при изменении экологических ситуации. Основным объектом исследования выступили заказники Волгоградской области, которые составляют $15 \%$ от общего числа ООПТ региона и занимают $26 \%$ от суммарной площади ООПТ, относятся преимущественно к зоологическому профилю. Вклад заказников в сохранение регионального биологического и ландшафтного разнообразия весьма значителен, особенно в условиях отсутствия в системе ООПТ Волгоградской области заповедников как приоритетной формы территориальной охраны природы. В качестве результата исследования получены оценочные значения природоохранной ценности, значимости и эффективности заказников Волгоградской области и выделены факторы, влияющие на выполнение ими природоохранной функции. Полученный результат можно рассматривать в качестве основы для разработки плана по увеличению эффективности каждого заказника.

Ключевые слова: биоразнообразие, особо охраняемые природные территории, Волгоградская область, заказник, природоохранная эффективность.

Введение. Заказники представляют собой форму территориальной охраны природы, которая направлена на сохранение ценных природных ландшафтов и отдельных видов растений и животных, а также поддержание экологической стабильности территории. Данная форма ООПТ в российской практике является одной из самых распространенных и играет важную роль в охране природы на национальном, региональном и местном уровне. Исторически заказники в России обеспечивали сохранность охотничьих угодий и вплоть до 50-х гг. 20 в. выполняли функцию восстановительных и резервных участков для хозяйственно ценных видов охотничьих животных. В настоящее время заказники с учетом своей широкой профильности (ботанические, зо0логические, ландшафтные, комплексные) и уровня охраны (федеральные и региональные) способны эффективно поддерживать природоохранную, экологическую и иную ценность природных объектов. Специфичность и многозадачность данной категории российских ООПТ подтверждается при соотнесении с категориями Международного союза охраны природы (МСОП). Так, федеральные заказники соответствуют в основном категориям Ib (территории с дикой природой) и IV (управляемый природный резерват). Заказник регионального значения в зависимости от профиля может соотноситься с такими категориями МСОП как IV (управляемый природный резерват), V (охраняемый ландшафт) и даже VI (территория устойчивого природопользования). Широ- кие возможности данной категории ООПТ по обеспечению охраны природных комплексов и объектов подтверждаются и спектром задач, закрепленных законодательством.

Материалы и методы. В соответствии с законом об «Особо охраняемых природных территориях» заказниками являются территории или акватории, которые имеют особое значение для сохранения и восстановления природных компонентов и поддержание экологического баланса. Заказники могут быть различного профиля: биологического, палеонтологического, гидрологического, геологического и комплексного [2]. Главными задачами заказников является сохранение и восстановление природных комплексов и компонентов; пропаганда и внедрение передового опыта охраны и воспроизводства диких животных, редких и исчезающих видов животных и растительного мира; ведение мониторинга состояния растений и животных, которые занесены в Красную книгу региона или России [5].

По состоянию на 2018 г. на территории Российской Федерации образовано 57 государственных заказников федерального значения. Занимаемая ими площадь равна 6,9 млн га (что составляет $2,9 \%$ от площади всех ООПТ России). Что касается заказников регионального значения, то их количество на 2017 г. составило 10492 единицы. Занимаемая ими площадь равна 121,8 млн га (52 \% от площади всех ООПТ России) [3].

Отличительными чертами сложившейся системы ООПТ Волгоградской области, 


\section{ЭКОЛОГИЯ И ПРИРОДОПОЛЬЗОВАНИЕ}

начавшей свое формирование в 80-х гг. 20 в. в условиях значительного хозяйственного освоения региона, является отсутствие в ее составе таких значимых форм территориальной охраны как заповедники и национальные парки. В результате чего основными элементами, выполняющими природоохранную и эколого-стабилизирующую роль становятся природные парки и заказники. По состоянию на 01.10.2019 на территории Волгоградской области функционирует 52 ООПТ регионального уровня, представленные следующими категориями: 7 природных парков; 8 государственных природных заказников; 18 памятников природы; 1 охраняемый ландшафт; 18 территорий, представляющих ценность для сохранения объектов растительного и животного мира, занесенных в Красные книги.

Основным объектом исследования выступили заказники Волгоградской области, которые по состоянию на конец 2018 г. составляют $15 \%$ от общего числа ООПТ региона, при этом занимая $26 \%$ от суммарной площади ООПТ. Система заказников региона начала формироваться в начале 1990-х гг. (17 заказников регионального уровня общей площадью 47,9 тыс. га). В Волгоградской области по количеству и занимаемой площади преобладают заказники зоологического профиля (охотничьи), и целью их создания выступает восстановления численности промысловых видов для их последующего хозяйственного использования [1;4].

Некоторые из государственных природных заказников, например, Куланинский, Лещевский и Кумылженский находятся на территории природных парков, как бы являясь их поддерживающей системой и повышая их природоохранную роль.

Заказники охватывают широкий спектр экосистем. Так, большую часть Задонского заказника занимают малонарушенные типчаково-ковыльные степи и пойменные леса и основными охраняемыми объектами являются стрепет, белая и серая цапли, косуля, кабан, горностай. В Кумылженском большие площади занимают разнотравно-типчаковоковыльные псамофитные степи на песчаных почвах, реликтовые и байрачные леса. В таких заказниках как Лещевский под охраной находятся водные экосистемы рек Волги,
Ахтубы, озер, ериков. Наибольшим разнообразием природных комплексов обладает Перещепновский заказник, получивший статус комплексного.

Природоохранная эффективность - это успешность выполнения определенной категорией ООПТ своей цели и природоохранных задач. Природоохранная эффективность складывается из успешной реализации пяти функций: эталонной (видовое богатство, ландшафтное разнообразие, чуждые и синантропные виды и экосистемы) рефугиумной (редкие и исчезающие виды и экосистемы), резерватной (охотничье-промысловые виды, крупные скопления животных, растения, имеющие утилитарную ценность), монументальной (природные объекты, имеющие выдающееся природоохранное или научно-познавательное значение) и эколого-стабилизирующей (смягчение последствий изменения климата, предотвращение деградации почв, защита берегов, обеспечение запасов воды и ее качества, воспроизводство ключевых и хозяйственно ценных видов). Процедура оценки природоохранной ценности ООПТ складывается из этапов, представленных на рисунке 1 [6].

Результаты и обсуждение. Зная природоохранную эффективность отдельных ООПТ, можно оценить насколько они значимы для региона, а также выяснить основные угрозы, которые мешают достичь полной эффективности. Ниже приведен расчет эффективности для каждого заказника Волгоградской области (см. табл. 1).

Анализируя таблицу 1, можно сделать вывод о том, что наибольшей природоохранной эффективностью обладает заказник Ольховский. Из всех пяти функций в заказнике реализуются только четыре. Эколого-стабилизирующая и рефугиумная функции достигают своего максимального значения - $100 \%$, эталонная и резерватная также находятся на высоком уровне - $75 \%$. Общая природоохранная эффективность находится на уровне $87 \%$, что является достаточно высоким показателем для региона. Такую высокую оценку заказник получил из-за наличия на ООПТ нетрансформированных экосистем (более $50 \%$ ).

Заказник Кумылженский также занимает высокую позицию среди заказников Волгоградской области с наиболее высокими по- 
А.В. Холоденко, А.В. Гребенникова. Перспективы повышения природоохранной эффективности

казателями природоохранной эффективности, которая равна 81,3 \%. Такую высокую оценку определяют рефугиумная и резерватная функции, достигающие оценки $100 \%$. Наибольший вклад в это значение вносит видовое богатство, которое превышает среднее для данного региона.
Заказник Дрофиный находится на 4 месте из 9 по природоохранной эффективности заказников Волгоградской области. Наибольший вклад в суммарную природоохранную ценность вносит рефугиумная функция, далее - резерватная, а наименьшую эталонная и эколого-стабилизирующая.

\begin{tabular}{|c|c|}
\hline $\begin{array}{c}\text { І этап - Оценка базовых показателей: } \\
\text { репрезентативность }(r) \text {, } \\
\text { контраст с окружением }(d) \\
\text { текущее состояние }(c) .\end{array}$ & $\begin{array}{c}\text { II этап - Оценка текущей } \\
\text { природоохранной эффективности: } \\
\text { природоохранная ценность }(V) \\
V=r+d \\
\text { природоохранная значимость }(I) \\
I=V \times\left(c / c_{\max }\right) \\
\text { природоохранная эффективность }(F) \\
F=\left(c / c_{\max }\right) \times 100\end{array}$ \\
\hline \multicolumn{2}{|c|}{$\begin{array}{c}\mathrm{A}=a \times i \times r \times p, \\
\text { где } a-\text { вероятный диапазон проявления, } i-\text { вероятная сила воздействия, } r- \\
\text { продолжительность восстановительного периода, } p-\text { вероятность реализации угрозы }\end{array}$} \\
\hline \multicolumn{2}{|c|}{$S=100-\left(\mathrm{A} \times 100 / \mathrm{A}_{\max }\right), \mathrm{A}_{\max }=256$} \\
\hline \multicolumn{2}{|c|}{$\begin{array}{l}\text { IV этап - Оценка устойчивости к долговременным изменениям природной среды } \\
\text { Консервативная устойчивость } C R=(L+T+S) / 3, \\
\text { где } L-\text { благоприятность географического положения, } T-\text { текущая и потенциальная } \\
\text { благоприятность территории, } S \text { - стабильность литогенной основы. } \\
\text { Динамическая устойчивость } D R=(X+N) / 2, \\
\text { где } X \text { - разнообразие экстразональных и реликтовых элементов, } N-\text { связность ООПТ }\end{array}$} \\
\hline \multicolumn{2}{|c|}{ Общая устойчивость $R=(C R+D R) / 2$} \\
\hline \multicolumn{2}{|c|}{$\begin{array}{c}\text { V этап - Оценка перспективной эффективности ООПТ } \\
\text { Текущая перспективная природоохранная эффективность в стабильных условиях } \\
E s=F \times(S / 100) \\
\text { Перспективная природоохранная эффективность в условиях значимых изменений среды } \\
E c h=F \times(S / 100) \times(R / 100)\end{array}$} \\
\hline
\end{tabular}

Рис. 1. Этапы оценки текущей и перспективной природоохранной эффективности [6]

Таблица 1

\section{Природоохранная эффективность заказников Волгоградской области}

\begin{tabular}{|c|c|c|c|c|c|c|c|c|c|c|c|c|c|}
\hline \multirow[t]{2}{*}{ Заказник } & \multicolumn{3}{|c|}{$\begin{array}{c}\text { Эталонная } \\
\text { функция }\end{array}$} & \multicolumn{3}{|c|}{$\begin{array}{c}\text { Рефугиумная } \\
\text { функция }\end{array}$} & \multicolumn{3}{|c|}{$\begin{array}{c}\text { Резерваторная } \\
\text { функция }\end{array}$} & \multicolumn{3}{|c|}{$\begin{array}{c}\text { Экостабильная } \\
\text { функция }\end{array}$} & \multirow{2}{*}{$\begin{array}{c}\text { Итоги, } \\
\text { \% }\end{array}$} \\
\hline & $V$ & $I$ & $F$ & $V$ & $I$ & $F$ & $V$ & $I$ & $F$ & $V$ & $I$ & $F$ & \\
\hline Дрофиный & 5 & 4,3 & 80 & 71 & 49,5 & 65,5 & 20 & 20 & 100 & 10 & 5 & 50 & 73,8 \\
\hline Задонский & 5 & 4,3 & 68,8 & 71 & 49,5 & 65,5 & 20,5 & 20,5 & 100 & 10 & 5 & 50 & 71 \\
\hline Куланинский & 5 & 4 & 75 & 71 & 49,5 & 68,5 & 20,5 & 20,5 & 100 & 13 & 6,5 & 50 & 73 \\
\hline Кумылженский & 4,8 & 4 & 75 & 131 & 131 & 100 & 20 & 20 & 100 & 2 & 1 & 50 & 81,3 \\
\hline Лещевский & 4,7 & 4 & 75 & 131 & 131 & 100 & 20 & 20 & 100 & 2 & 1 & 50 & 68 \\
\hline Ольховский & 5 & 4,3 & 75 & 131 & 131 & 100 & 36 & 30 & 75 & 7 & 1,7 & 100 & 87 \\
\hline Перещепнов ский & 5,5 & 1 & 87,5 & 23 & 11,5 & 50 & 4 & 2 & 50 & 7 & 2,8 & 75 & 65 \\
\hline Раздорский & 4,5 & 3,1 & 62,5 & 23 & 11,5 & 65 & 1,5 & 2,8 & 75 & 8 & 6 & 100 & 71,8 \\
\hline Чернополянский & 4,7 & 2,8 & 75 & 23 & 11,5 & 65 & 1,5 & 4,8 & 50 & 8 & 6 & 100 & 68,8 \\
\hline Среднее & 4,9 & 3,5 & 74,8 & 75 & 64 & 75 & 16 & 15 & 83 & 7 & 4 & 70 & 75 \\
\hline
\end{tabular}




\section{ЭКОЛОГИЯ И ПРИРОДОПОЛЬЗОВАНИЕ}

За Дрофиным заказником по природоохранной эффективности следует Куланинский заказник. Заказник реализует четыре функции из пяти, исключение составляет монументальная. Наибольший вклад в природоохранную значимость вносит резерватная функция, далее идет эталонная и рефугиумная, на последнем месте находится эколого-стабилизирующая. Общая оценка составляет $73 \%$.

На 6 месте из 9 находится заказник Раздорский. В ООПТ реализуется 4 функции из 5 возможных, исключение составляет монументальная функция. Самым максимальным значением характеризуется эколого-стабилизирующая функция и она достигает $100 \%$. На втором месте по значимости находится резерватная функция (75 \%), далее следует эталонная и рефугиумная. Общая эффективность заказника находится на уровне $71,8 \%$.

После Раздорского заказника по своей эффективности следует заказник Задонский. На территории заказника реализуются четыре из пяти функций, исключая монументальную. Наибольший вклад в суммарную природоохранную эффективность вносит резерватная функция, далее следует эталонная и рефугиумная, на последнем месте находится эколого-стабилизирующая. Общая природоохранная эффективность заказника составляет $71 \%$.

На предпоследнем месте находятся заказники Чернополянский и Лещевский. В заказниках реализуется 4 функции из 5-ти возможных. Максимального значения достигает эколого-стабилизирующая функция, далее эталонная, затем рефугиумная и резерватная. Общая оценка природоохранной эффективности составляет 68 \%. Низкая оценка обусловлена тем, что большая часть территории занята сельскохозяйственными территориями, что обуславливает наличие трансформированных экосистем, а также чуждых и синантропных видов.

На последнем месте находится Прещепновский заказник. Общая природоохранная эффективность заказника оценивается на $65 \%$. Наибольший вклад в это значение вносит эталонная функция, затем эколого-стабилизирующая, далее рефугиумная и резерватные функции. Несмотря на то, что территория в большой степени не нарушена, ее площадь в срав- нении с другими не столь высока для обеспечения сохранности ценных и редких видов и сообществ.

Методика М.С. Стишова [6] позволяет выявить перспективную природоохранную эффективность, сущность которой заключается в оценке природных и антропогенных угроз и оценке безопасности ООПТ.

Основными антропогенными угрозами являются антропогенные пожары, незаконное природопользование на территории ООПТ и разрешенные на территории виды деятельности. Все потенциальные угрозы антропогенного происхождения имеют локальное значение и характеризуются незначительной силой воздействия. При условии устранения угроз, безопасность может быть повышена до $98 \%$.

Из 3072 (100\%) возможных угроз в заказниках на данный момент имеют место быть лишь 124 (4 \%), что является весьма высоким показателем для региона. Суммарная актуальность антропогенных угроз превышает природные, хоть и не существенно, поэтому их можно считать одинаково значимыми для заказников. Все угрозы контролируются на территории ООПТ и на местном уровне.

Используемая методика оценки природоохранной эффективности дает возможность вычислить устойчивость заказников к долговременным изменениям среды. Она разделяется на консервативную и динамическую устойчивость. Консервативная в свою очередь состоит из географического положения, площади и ландшафтного разнообразия, устойчивости литогенной основы.

Благоприятность географического положения составляет $80 \%$. Это значение определяется тем, что ООПТ располагаются вдали от границ крупного климатически обусловленного физико-географического подразделения. Площадь заказников велика, что означает, что при смещении климатических физикогеографических границ заказники останутся в прежнем климатическом диапазоне. Устойчивость литогенный основы достигает максимального значения. Ведущие ланшафтообразующие компоненты малочувствительны к климатическим изменениям, в результате чего литогенная основа претерпевает несущественные изменения. 
Таким образом, консервативная устойчивость заказников находится на уровне $95 \%$. Почти все показатели консервативной устойчивости характеризуются максимальными значениями. Заказники находятся в положении, обеспечивающим полное сохранение природных комплексов, при условии смещения климатических условий или обусловленных физико-географических районов.

Динамическая устойчивость складывается из разнообразия экстразональных и реликтовых элементов, а также связности ООПТ с другими ненарушенными и малонарушенными территориями. При максимальном показателе связанности (100 \%) заказники характеризуются наличием отдельных экстразональных сообществ и экосистем (50 \%), разнообразие которых, однако, может быть повышено путем оптимизации территории. Таким образом, динамическая устойчивость находится на уровне $75 \%$, что гораздо ниже консервативной.

Зная динамическую устойчивость и консервативную, можно вычислить общую устойчивость заказников Волгоградской области к долговременными изменениям природной среды (табл. 2).

Показатель консервативной устойчивости для территории заказников достаточно высок - 89 \% и более повышен быть не может ввиду отсутствия возможностей оптимизации его составляющих. Показатель динамической устойчивости более низок, составляя всего $75 \%$, но при оптимизации территории заказников может быть повышен до $100 \%$.

Общий показатель устойчивости территории заказников Волгоградской области к долговременными изменениям природной среды составляет $82 \%$ и может быть повышен до 95 \% при повышении разнообразия экстра- зональных элементов путем оптимизации территории.

Выводы. Средне значение текущей природоохранной эффективности для категории «заказник» в Волгоградской области составляет 74,3 \%. Это значение достаточно высоко, но отличается от оптимального (100\%). Зачастую это связано с высоким показателем ценности, но низкой природоохранной значимостью из-за ухудшающегося текущего состояния экосистем на территории заказников. Репрезентативность как базовый показатель природоохранной ценности ООПТ играет ключевую роль в формировании итогового значения природоохранной эффективности, потому что каждый заказник создан для сохранения и воспроизводства, в случае с Волгоградской областью, охотничьих ресурсов, сохранения среды их обитания и условий их размножения, нагула, отдыха и путей миграции. Также, высокие значения эффективности экологостабилизирующей, эталонной, рефугиумной и резерватной функций повышает значимость заказников в системе ООПТ региона в целом и формировании экологического каркаса в частности.

Эффективность, однако, может быть повышена до оптимальных в сложившихся региональных условиях 77 \% при условии исключения влияния на ООПТ антропогенных угроз (пожаров, разрешенных на ООПТ видов деятельности).

На основе анализа основных угроз, можно предложить следующие направления повышения эффективности заказников:

1) проведение мероприятий для устранения причин пожаров, как антропогенных, так и природных;

2) поддержание режима особого природопользования на территории заказников;

Таблиия 2

Перспективная природоохранная эффективность заказников Волгоградской области

\begin{tabular}{|l|c|c|}
\hline \multicolumn{1}{|c|}{ Показатели } & Текущая оценка & Потенциальная оценка \\
\hline Консервативная устойчивость, $\boldsymbol{C R}$ & 89 & 89 \\
\hline Динамическая устойчивость, $\boldsymbol{D R}$ & 75 & 100 \\
\hline Общая устойчивость, $\boldsymbol{R}$ & 82 & 77 \\
\hline $\begin{array}{l}\text { Перспективная эффективность в стабильных } \\
\text { условиях среды, } \boldsymbol{E} \boldsymbol{s}\end{array}$ & 75 & 69 \\
\hline $\begin{array}{l}\text { Перспективная эффективность в условиях } \\
\text { значимых изменений среды, } \boldsymbol{E} \boldsymbol{c h}\end{array}$ & 58 & 67 \\
\hline
\end{tabular}




\section{ЭКОЛОГИЯ И ПРИРОДОПОЛЬЗОВАНИЕ}

3) совершенствование экологического каркаса Волгоградской области путем развития сети экологических коридоров заказников с другими ООПТ.

Оценка текущей и перспективной природоохранной эффективности может служить основой для принятия управленческих решений для повышения результативности функционирования отдельных категорий ООПТ и их системы в сложившихся на территории региона природно-экологических условиях.

\section{СПИСОК ЛИТЕРАТУРЫ}

1. Приказ комитета природных ресурсов, лесного хозяйства и экологии Волгоградской области от 10.01.2019 № 63 «Об утверждении перечней особо охраняемых природных территорий регионального и местного значения». - Электрон. текстовые дан. - Режим доступа: http:// docs.cntd.ru/document/550317915 (дата обращения: 15.01.2019).

2. Федеральный закон от 14.03.1995 № 33-Ф3 «Об особо охраняемых природных территориях» (с изменениями и дополнениями). - Электрон. текстовые дан. - Режим доступа: http://base.garant.ru/ 10107990/\#ixzz5zeP9715q (дата обращения: 15.01.2019).

3. Государственный доклад «О состоянии и об охране окружающей среды Российской Федерации в 2017 году». - М. : Минприроды России ; Кадастр, 2018. - 888 с.

4. Доклад «О состоянии окружающей среды Волгоградской области в 2017 году» / ред. колл. : В. Е. Сазонов [и др.] ; комитет природных ресурсов, лесного хозяйства и экологии Волгоградской области. - Волгоград : ТЕМПОРА, 2018. - 300 c.

5. Иванов, А. Н. Охраняемые природные территории : учебное пособие / А. Н. Иванов, В. П. Чижова. - М. : Изд-во Моск. ун-та, 2003. - 119 с.

6. Стишов, М. С. Методика оценки природоохранной эффективности особо охраняемых природных территорий и их региональных систем. M. : WWF России, 2012. - 284 c.

\section{REFERENCES}

1. Prikaz komiteta prirodnyh resursov, lesnogo hozjajstva i jekologii Volgogradskoj oblasti ot 10.01.2019 № 63 «Ob utverzhdenii perechnej osobo ohranjaemyh prirodnyh territorij regionalnogo $i$ mestnogo znachenija». URL: http://docs.cntd.ru/ document/550317915 (accessed January 15, 2019).

2. Federalnyj zakon ot 14.03.1995 № 33-FZ "Ob osobo ohra-njaemyh prirodnyh territorijah" (s izmenenijami i dopolnenijami). URL: http:// base.garant.ru/10107990/\#ixzz5zeP9715q (accessed January 15,2019 ).

3. Gosudarstvennyj doklad «O sostojanii i ob ohrane okruzhajushhej sredy Rossijskoj Federacii v 2017 godu». Moscow, Minprirody Rossii, Kadastr, 2018. 888 p.

4. Sazonov V.E. et al. eds. Doklad «O sostojanii okruzhajushhej sredy Volgogradskoj oblasti v 2017 godu». Volgograd, TEM-PORA, 2018. $300 \mathrm{p}$.

5. Ivanov A.N., Chizhova V.P. Ohranjaemye prirodnye territorii: Uchebnoe posobie. Moscow, Izdvo Mosk. un-ta, 2003. $119 \mathrm{p}$.

6. Stishov M.S. Metodika ocenki prirodoohrannoj jeffektivnosti osobo ohranjaemyh prirodny territorij i ih regionalnyh sistem. Moscow, WWF Rossii, 2012.284 p.

\section{Information about the Authors}

Anna V. Kholodenko, Candidate of Sciences (Geography), Associate Professor, Department of Ecology and Nature Resources Management, Volgograd State University, prosp. Universitetskiy, 100, 400062 Volgograd, Russian Federation, kholodenko@volsu.ru.

Aleksandra V. Grebennikova, Student (Bachelor), Department of Ecology and Nature Resources Management, Volgograd State University, prosp. Universitetskiy, 100, 400062 Volgograd, Russian Federation, alexsandramalik@yandex.ru.

\section{Информация об авторах}

Анна Викторовна Холоденко, кандидат географических наук, доцент кафедры экологии и природопользования, Волгоградский государственный университет, просп. Университетский, 100, 400062 г. Волгоград, Российская Федерация, kholodenko@volsu.ru.

Александра Владимировна Гребенникова, студент (бакалавр) кафедры экологии и природопользования, Волгоградский государственный университет, просп. Университетский, 100, 400062 г. Волгоград, Российская Федерация, alexsandramalik@yandex.ru. 